[Aus der Infektionsabteilung des Rud. Virchow-Krankenhauses in Berlin.] (Dirig. Arzt: Privatdozent Dr. Jochmann.)

\title{
Über Infektionen mit Paratyphusbazillen des Typhus A und Befunde von verwandten Bakterien.
}

\section{Von}

Dr. Christian Schöne,

früherem Assistenten der Abteilung.

Im März 1898 veröffentlichte Gwyn (1) die Beobachtung eines Falles aus Johns Hopkins Hospital in Baltimore, der das Bild des Abdominaltyphus bot: Hohe Temperaturen, palpablen Milztumor, Diazoreaktion im Urin, Roseolen und Darmblutungen. Typhusbazillen wurden nie gefunden und nie vom Serum agglutiniert. Aus dem Blut züchtete G w yn einen Bacillus und beschrieb eingehend seine morphologischen Eigenschaften und sein Verhalten auf den gebräuchlichen Nährböden. Er nannte ihn danach einen Para-Colonbacillus, wollte nieht unbedingt das Bedenken zurückweisen, ob derselbe nicht vielleicht nur eine Sekundärinfektion während der Krankheit veranlaBt habe, betonte aber, daB das Krankenserum nie Typhusbazillen agglutinierte, wohl aber stets den isolierten. Es folgten weitere Beobachtungen von Amerikanern, die aber nie so exakt und für die heutige Kritik befriedigend waren wie diese erste Beschreibung von Gwyn.

Grundlegende Beobachtungen über dieselben Bakterien wurden dann im Jahre 1901 von Schottmüller (2) gemacht, der zuerst den Namen Paratyphus gebrauchte und zwei Typen voneinander trennte. Er konnte über zwei Fälle von reiner Infektion mit dem $G$ wynschen Bacterium, das ihm nicht bekannt war, berichten, während Brion und Kayser (3) bald darauf den Nachweis des gleichen Bacteriums im Blut eines an Zeitschr. f. Hygiene. LXV 
Gonorrhoe erkrankten Mädchens veröffentlichten und in dieser Arbeit ihre, die seltenere Varietät mit Typus A, die häufigere mit Typus B bezeichneten. Man hat später nicht nur in der deutschen, sondern auch in der ausländischen Literatur diesen selteneren Typus des Paratyphusbacillus den Brion-Kayserschen genannt, den Paratyphus B den Schottmüller schen, aber gröBeres Anrecht auf die Namensbezeichnung des ersteren hätte der Amerikaner $\mathrm{Gw}$ yn, der ihn zuerst gesehen und charakterisiert hat. Die folgenden Jahre haben gezeigt, daB der Typus A viel seltener und weniger schwere Erkrankungen beim Menschen erzeugt als der andere, und dieser Standpunkt wird auch von Kutscher in der Abhandlung über Paratyphus im ersten Ergänzungsband des KolleWassermannschen Handbuches eingenommen.

Auch aus den letzten Berichten ist seltener seine selbständige und bösartige Rolle als Kranheitserreger ersichtlich als die Neigung zu sekundären und Mischinfektionen und sein Vorkommen bei chronischen Krankheitsbildern. Nach Nicolle und Cathoire (4) waren ron 64 klinischen Typhusfällen bei einer Epidemie der tunesischen Besatzung im Jahre 190516 durch den Paratyphusbacillus A verursacht. Die Schlüsse werden zum gröBten Teil aus den Ergebnissen der Agglutination gezogen. Doch wurden die Bazillen von einem Kranken aus dem Blut, von einem anderen aus dem Trin isoliert und in den folgenden Mitteilungen auf Grund des Vergleiches mit bekannten Stämmen genau gekennzeichnet. Die Höhe des Agglutinationstiters war im allgemeinen sebr gering, nur in einem Falle betrug sie 1:2000, dagegen fielen die Proben mit Typhusund Paratyphus B-Bazillen entweder negativ oder sehr schwach aus. Es wird von den Autoren besonders darauf aufmerksam gemacht, daB in Anbetracht des rapiden Abfalles des Agglutinationstiters in der Apyrexie eine retrospektive Diagnose des Paratyphus A nicht möglich sei. Die Verfasser haben den Eindruck, daB gewöhnlich die Fälle von Paratyphus A günstig verlaufen.

Weiterhin sind inzwischen aber auch Mitteilungen über tödlich verlaufene Fälle gemacht worden. Castellani (5) beobachtete bei Epidemien von Typhus und Paratyphus in Ceylon dort zum ersten Mal fünf Fälle, die nur durch den Typus A hervorgerufen waren. Von diesen tam einer zur Sektion, wobei sich im unteren Teile des Ileum mehrere den typhösen absolut gleichende Geschwüre und vergröBerte Mesenterialdrüsen fanden. Diese, die Geschwüre und die Milz wurden bakteriologisch untersucht, aber keine Typhusbazillen gefunden, sondern in Milz und Mesenterialdrüsen Paratyphus A-Bazillen in Reinkultur, in den Geschwüren gemeinsam mit Coli- und anderen Bakterien. Es werden in der jüngsten Literatur weitere Beobachtungen mitgeteilt, in denen der 
Paratyphusbacillus A besonders bei Mischinfektionen mit anderen Bakterien gefunden wurde. Von Castellani in demselben Bericht vergesellschaftet mit Staphylococcus albus, und von Baermann und Eckersdorff (6) aus Sumatra, die den Bacillus bei 8 Fällen zweimal von 6 untersuchten im Blut fanden. Diese berichten von zwei sezierten Fällen, die aber keine reinen Infektionen darstellten, sondern einmal mit schwerer gonorrhoischer Allgemeinerkrankung, das andere Mal mit Tertiana vergesellschaftet waren. Bei den mehr chronisch verlaufenden Fällen fanden sie bemerkenswerter Weise im Stuhl häufig isolierte Eiterklümpchen. Nach den anatomischen Untersuchungen betraf der Weitergang der Erkrankung nicht die follikulären Apparate, sondern namentlich der Dickdarm war diffus katarrhaliseheitrig verändert. Auch nach diesen Mitteilungen erreichte die Agglutination der Krankensera als höchste Werte gewöhnlich 1:320, nur einmal betrug sie 1:700. Die Bazillen wurden bei den Sektionen nur im Darm und in den Mesenterialdrüsen, nicht in Milz, Leber und Galle gefunden. In einem Falle von 13 Jahre dauernder chronischer Enteritis fand Bondi (7) im Stubl die Paratyphus A-Bazillen und einen Agglutinationstiter des Serums von 1:2000. Uther die ätiologische Bedeutung spricht er sich zurüchhaltend aus, doch kann man sagen, daß dieser Befund sehr wohl mit den übrigen bisher gemachten Erfahrungen im Einklang steht, wonach dieser Bacillus besonders häufig als Erreger milderer Krankheitsprozesse oder bei Mischinfektionen beobachtet wird.

Morgan (8), von dem Kutscher im Handbuch von Kolle und Wassermann referiert, daB er den Paratyphus A-Bazillus aus dem Tierdarm isolierte, fand tatsächlich nur Bakterien, die dem genannten sehr nahe standen. Er erhielt bei Untersuchungen von Fäzes und Abschabungen von der Darmschleimhaut einiger Kaninchen, Mieerschweinchen, Schweine, Schafe, von einem Kalb und einem Pferde 10 Kulturen, die in ihrem Verhalten gegenüber den Kohlehydraten, sowie in ihren sonstigen Eigenschaften im wesentlichen dieselben Merkmale wie Paratyphus ABazillen aufwiesen, in ihren Reaktionen gegenüber vier künstlichen Paratyphus A-Immunseris jedoch gar keine Verwandtschaft mit diesen zeigten. Er nennt dieselben in seiner Veröffentlichung cultures of the Paratyphoid A group, bisweilen freilich auch of the Paratyphoid type und meint, dab sie möglicherweise zu einer anderen Spezies derselben Gruppe gehören.

Uhlenhuth (9) hat später tatsächlich bei Gelegenheit von Untersuchungen über die Schweinepest aus den Organen künstlich mit keimfreien Filtraten von Schweinepestvirus infizierter Ferkel neben anderen auf drei Stämme von Bazillen gezüchtet, die den Paratyphus A-Formen nicht nur kulturell glichen, sondern auch von einem Paratyphus A-Serum mit dem Titer $1: 2000$ bis zur Grenze agglntiniert wurden. Gleichwohl 
spricht er, wohl auf Grund der Erfahrungen über die Schwierigkeit der Identifizierung von Bakterien aus der Paratyphus B-Gruppe, nur von Paratyphus A-ähnlichen Stämmen.

Anschließend an diese Literaturberichte will ich einige Untersuchungen mitteilen, die sich den genannten anreihen. Im Juli 1908 wurde auf der Infektionsabteilung des Rudolf Virchow-Krankenhauses ein Mädchen von 23 Jahren wegen akuten Brechdurchfalls behandelt. Sie bezog ihre Erkrankung auf den GenuB von Salamiwurst; mehrere andere Personen, die gemeinschaftlich mit ihr davon gegessen hatten, waren aber gesund geblieben. Reste der Wurst waren noch vorhanden. Der gröBte Teil erschien vollkommen einwandfrei, während das Stück, von dem die Kranke gegessen hatte, miBfarben grau und unappetitlich aussah. Hiervon wurden Proben in sterile Bouillonröhrchen gebracht, weiter auf Drigalskiplatten Ausstriche gemacht und auf diesen am folgenden Tage mehrere blau wachsende Kolonien erhalten, die erst später die Umgebung leicht röteten. Weitere Prüfungen von Reinkulturen dieses Stammes ergaben nur geringe Eigenbewegung, Wachstum auf Kartoffel wie Typhus- und Paratyphus ABazillen, keine Verflüssigung der Gelatine, keine Produktion von Indol in Bouillon und Peptonlösung, in Milch nach wochenlanger Beobachtung keine Gerinnung, aber Säurebildung, Trübung und nur leichte Rötung der Lackmusmolke, Zerlegung von Traubenzucker, Maltose und Mannit in Säure und Gas, keine Zerlegung von Rohrzucker, Hemmung des Wachstums auf Malachitgrünnährböden in demselben MaBe wie bei Paratyphus A und Agglutination durch ein Paratyphus A-Serum aus dem Institut für Infektionskrankheiten mit dem Titer $1: 800$ bis zu einer Verdünnung von $1: 200$, durch ein solches, das ich mir selbst durch Behandlung eines Kaninchens mit einem Paratyphus A-Stamm herstellte, mit dem Titer $1: 12000$ bis zur Verdünnung von 1:500. Sorgfältige und mehrfach wiederholte Untersuchungen des Blutes, des Stuhles und Urins der Kranken ließen diese Bakterien nicht finden, ebensowenig konnte eine Agglutination durch das Serum festgestellt werden. Die Krankheit dauerte nur wenige Tage, verlief ohne Fieber und bestand in anfänglichem Erbrechen und Durchfall und noch kurze Zeit anhaltenden Kopf-, Leib- und Rückenschmerzen, bot mithin keine schweren Symptome. Der. Beweis eines ursächlichen Zusammenhanges der gefundenen Bakterien konnte somit zwar nicht erbracht werden, immerhin erscheint das Auffinden dieses dem Paratyphus A ähnelnden Stammes in einer Wurst, deren GenuB für den Menschen üble Folgen hatte, bemerkenswert.

Die Wurst war von Schweinefleisch hergestellt, und dieses stammte ron Tieren aus dem Berliner Zentralviehhof. Durch freundliches EntgegenKommen des Direktors desselben ist es mir dann möglich gewesen, weitere 
Untersuchungen über das Vorkommen Paratyphus A-ähnlicher Bakterien vorzunehmen. Ich untersuchte den Dünn- und Dickdarminhalt von 100 als einwandsfrei befundenen Schweinen, die aus Pommern, Mecklenburg und Brandenburg stammten, in der Weise, daB ich von den Schleimhäuten der frisch geschlachteten Tiere Abschabungen machte, diese in sterile Bouillonröhrchen brachte, nach einem oder mebreren Tagen davon auf Malachitgrün- und Drigalskiplatten ausstrich und von allen nur entfernt verdächtigen Kolonien, d. h. solchen, die nicht sicher von typischen Colibakterien herrübrten, orientierende Deckglasagglutinationen mit Paratyphus A-Serum anstellte, darauf die gefundenen Stämme isolierte und weiter prüfte. Meine Ergebnisse lassen sich kurz dahin zusammenfassen, daB ich 20 agglutinable Stämme fand, die zwar den Milchzucker nicht gleichmäBig schnell zerlegten, sonst aber alle Charakteristica des Colibacillus aufwiesen. Etwa zur Hälfte zeigten sie lebhafte Eigenbewegung, zur Hälfte nur schlechte oder molekulare, alle bildeten sie Indol und brachten Milch innerhalb von 24 Stunden zur Gerinnung.

Ich stellte nun weiter dieselben bakteriologischen Untersuchungen auch bei Fäzes von 50 Menschen an, die teils gesund waren, teils an den verschiedensten Krankheiten litten, und isolierte auch bei drei von ihnen Colistämme, die von Paratyphus A-Serum agglutiniert wurden.

Die Höhe der Mitagglutination einiger Stänme durch zwei verschiedene Paratyphus A-Sera und durch ein Serum, das ich mir mit einem der vom Schwein erhaltenenen Stämme durch intravenöse Injektionen bei einem Kaninchen herstellte, möge in den folgenden Tabellen mitgeteilt sein.

+++ bedeutet Agglutination innerbalb von 10 Minuten, ++ von 1 bis 2 Stunden, + von 24 Stunden. Es machte keinen Unterschied in der Schnelligkeit oder Art der Agglutination aus, ob die Röhrchen bei $37^{\circ}$ oder $18^{\circ}$ gehalten wurden.

\begin{tabular}{|c|c|c|c|c|c|}
\hline \multirow{2}{*}{ Herkunft der Stämme } & \multicolumn{5}{|c|}{$\begin{array}{c}\text { Paratyphus A-Serum (Titer } 1: 800)^{\text {in }} \text { in der Ver- } \\
\text { dünnung } 1:\end{array}$} \\
\hline & 150 & 200 & 300 & 600 & 800 \\
\hline Paratyphus A. . . . & $+\div+$ & $+t+$ & ++ & +++ & ++ \\
\hline Mensch 1, Schwein 5. & $+t+$ & ++ & ++ & ++ & - \\
\hline Mensch 2 und 3 . . . & +++ & ++ & + & - & - \\
\hline Wurst, Schwein 1 und 20 & ++ & ++ & - & - & - \\
\hline Schwein 10 und 15. & + & - & - & - & - \\
\hline
\end{tabular}


Christian Schöne:

\begin{tabular}{|c|c|c|c|c|}
\hline \multirow{2}{*}{ Herkunft der Stämme } & \multicolumn{4}{|c|}{$\begin{array}{c}\text { Paratyphus A-Sernm (Titer } 1: 12000 \text { ) in Ver- } \\
\text { dünnungen von } 1:\end{array}$} \\
\hline & 200 & 500 & 600 & 12.000 \\
\hline Paratyphus A . . . . & +++ & ++ & $++t$ & + \\
\hline $\begin{array}{l}\text { Wurst, Menseh } 1 \text { und } 2 \text {, } \\
\text { Schwein } 10 \text { und } 20\end{array}$ & +++ & $\stackrel{+}{++}$ & - & - \\
\hline Schwein 1 und 5 . . & ++ & - & - & - \\
\hline
\end{tabular}

\begin{tabular}{|c|c|c|c|c|c|c|}
\hline \multirow{2}{*}{ Herkunft der Stämme } & \multicolumn{6}{|c|}{$\begin{array}{c}\text { Immunserum von Stamm Schwein } 20 \text { (Titer } 4000 \text { ) } \\
\text { in Verdünnungen von } 1 \text { : }\end{array}$} \\
\hline & 80 & 100 & 400 & 800 & 1000 & 4000 \\
\hline Schwein 20 & $+t+$ & $++t$ & +++ & $+t+$ & +++ & ++ \\
\hline Mensch 1 . . . . & $+t+$ & +++ & ++ & + & - & - \\
\hline Wurst, Mensch 3, Schwein 5 & +++ & +++ & ++ & - & - & - \\
\hline Schwein 1 and 10 . . & ++ & ++ & - & - & - & - \\
\hline Paratyphus A, Schwein 15 & + & - & - & - & - & - \\
\hline
\end{tabular}

Ein Tergleich zwischen den beiden ersten Tabellen veranschaulicht deutlich den Vorzug eines Serums von hohem spezifischen Titer, da bei diesem die Mitagglutination der am stärksten beeinflubten Stämme nicht nur relativ, sondern sogar absolut geringer ausfällt als bei dem mit geringem Titer $(1: 12000$ mit $1: 500$ Beeinflussung gegen $1: 800$ mit $1: 600$ Beeinflussung).

Absättigungsversuche wurden in der Weise ausgeführt, daB in 7 bis $8^{\text {cen }}$ Immunserum von erheblicher Konzentration (1:50 und 1:100) so lange Kulturmasse des homologen Stammes verrieben wurde, bis keine Agglutination mehr erfolgte, worauf dann eine Prüfung der anderen Stämme stattfand. Diese ließen sich dann sämtlich gleichfalls nicht mehr beeinflussen, wurden also von dem nichtgesättigten Serum nur mitagglutiniert.

Diese Befunde bilden gewissermaßen eine Ergänzung der von Morgan mitgeteilten. Derselbe isolierte Stämme, die zwar alle wesentlichen kulturellen, aber keine serologischen Reaktionen mit Paratyphus A-Bazillen gemeinsam hatten, ich dagegen solche mit umgekehrtem Verbalten. Als wesentliches Ergebnis kann die Tatsache gelten, daB es Bakterien gibt, die in gleicher Weise mit den gemeinen Coli- und den Paratyphusbazillen vom Typus A verwandt und mithin als Zwischenstufen zwischen beiden anzusehen sind, und dab mit diesem Nachweis auch das im Einklang steht, was wir über die Pathogenitätsverhältnisse der hier in Frage stehenden 
Bakterien sagen können. Müssen die Paratyphus A-Bazillen im allgemeinen als nicht eben gefährliche Krankheitserreger, immerhin aber als Krankheitserreger gelten, hingegen die gewöhnlichen Colibazillen nicht, so gibt es Zwischenstufen, deren Pathogenität für Menschen noch nicht erwiesen und wenn überhaupt vorhanden, sehr gering sein muB.

Die hier mitgeteilten Untersuchungen, die sehr viel Material von Nährböden erforderten, wurden mit den Hilfsmitteln der Infeltionsabteilung des Rudolf Virchow-Krankenhauses und des mit ihr in Verbindung stehenden Instituts für Infektionskrankheiten ausgeführt und zum Teil im Breslauer Garnisonlazarett, wo ich die sehr dankenswerte Unterstützung von Hrn. Stabsarzt Dr. Bock fand, weitergeführt und ergänzt.

\section{Literatur.}

1. Gwyn, Johns Hopkins Hospital Bulletin. 1898. Vol. IX.

2. Schottmüller, Diese Zeitschrift. 1901.

3. Brion und Kayser, Münchener med. Wochenschrift. 1902.

4. Nicolle et Cathoire, Compt. Rend. Soc. Biol. 1906.

5. Castellani, Lancet. 1907. I.

6. Baermann und Eckersdorff, Berliner klin. Wochenschrift. 1909.

7. Bondi, Wiener klin. Wochenschrift. 1909.

8. Morgan, The British Med. Journ. 1905.

9. Uhlenhuth, Arbeiten a. d. Kaiserl. Gesundheitsamt. 1908. Bd. XXVII. 